\title{
Tissue-specific and allele-specific replication timing control in the imprinted human Prader-Willi syndrome region
}

\author{
Preethi H. Gunaratne, ${ }^{1}$ Mitsuyoshi Nakao, ${ }^{1}$ David H. Ledbetter, ${ }^{1,3}$ James S. Sutcliffe, ${ }^{1}$ and \\ A. Craig Chinault ${ }^{1,2}$ \\ Departments of ${ }^{1}$ Molecular and Human Genetics and ${ }^{2}$ Biochemistry, Baylor College of Medicine, Houston, Texas, 77030 \\ $\mathrm{USA}_{;}{ }^{3}$ National Center for Human Genome Research, National Institutes of Health, Bethesda, Maryland 20892 USA
}

\begin{abstract}
To examine the relationship between replication timing and differential gene transcription in tissue-specific and imprinted settings we have studied the replication timing properties of the human Prader-Willi syndrome (PWS) region on human chromosome 15q11-13. Interphase fluorescence in situ hybridization with an overlapping series of cosmid clones was used to map a PWS replication timing domain to a 500- to 650-kb region that includes the SNRPN gene. This PWS domain replicates late in lymphocytes but predominantly early in neuroblasts, with replication asynchrony observed in both tissues, and appears to colocalize with a genetically imprinted transcription domain showing prominent expression in the brain. A 5- to 30-kb deletion in the ${ }^{\prime}$ region of SNRPN results in the loss of late replication control of this domain in lymphocytes when the deleted chromosome is inherited paternally. This potential allele-specific replication timing control region also appears to colocalize with a putative imprinting control region that has been shown previously to abolish the expression of three imprinted transcripts in this same region.
\end{abstract}

[Key Words: Replication timing; genetic imprinting; Prader-Willi syndrome; SNRPN gene]

Received September 21, 1994; revised version accepted February 16, 1995.

A general association between replication timing and gene transcription properties of mammalian chromosomal regions has been apparent for decades. The mammalian genome is replicated as noncontiguous blocks of DNA under a reproducible program of temporal control. For example, substitution of bromodeoxyuridine (BrdU) into DNA during the first or last half of S-phase followed by fluorescence microscopy revealed distinct banding patterns on metaphase chromosomes (Latt 1973; Hand 1978). These incorporation bands appear to coincide with G-negative and G-positive bands (Holmquist et al. 1982) and have been estimated to be made up of 10-20 replicons (Edenberg and Huberman 1975). In general, regions that have a high density of actively transcribed genes appear to be replicated early in S-phase, and heterochromatic regions and euchromatin that are transcriptionally inert appear to replicate late in S-phase (Goldman et al. 1984; Holmquist 1987). An extreme example of such a correlation is associated with $\mathrm{X}$-chromosome inactivation in eutherian mammals. One of the two X chromosomes in female cells is transcriptionally active, whereas most genes on the inactive $\mathrm{X}$ chromosome are silent. At the cytogenetic level the two homologs appear to replicate asynchronously in S-phase

${ }^{4}$ Corresponding author. with the active $\mathrm{X}$ chromosome being replicated early in $\mathrm{S}$-phase and the inactive $\mathrm{X}$ chromosome being replicated late in S-phase (Taylor 1960; Morishima et al. 1962; Brown 1966).

More recently, it has been shown that although the patterns are much more complex at higher resolution, a close link between replication and transcription is still maintained. Hybridization of newly replicated DNA isolated from different S-phase windows to Southern blots containing DNA from various genes or, conversely, hybridization of specific DNA probes to slot blots containing nascent strand DNA from different periods of S-phase indicate that every gene analyzed thus far is replicated in a defined time window (Goldman et al. 1984; Holmquist 1987). The replication timing of some genes, such as the $\beta$-globin gene cluster, skeletal muscle actin genes, immunoglobulin variable region genes, and the cystic fibrosis $(\mathrm{CF})$ gene region in human and the $5 \mathrm{~S}$ RNA genes in Xenopus, have been shown to be under developmental control, with the gene regions replicating early in expressing tissues and late in nonexpressing tissues (Holmquist 1987; Epner et al. 1981; Dhar et al. 1989; Selig et al. 1992). Even on the X chromosome it has been shown that there is a local level of control that results in an allele-specific correlation between gene transcription and relative time of replication at the gene level that is not obvious at the cytogenetic level 
(Schmidt and Migeon 1990; Boggs and Chinault 1994; Torchia et al. 1994).

Although it is difficult to assess whether replication timing plays a causal role in control of gene expression or is a result of it, the intimate relationship between the two parameters warrants investigation. The replication timing profiles of genetically imprinted regions are of special interest as there the expression of genes occurs from only one of the homologs. The Prader-Willi/Angelman Syndrome region at chromosome 15q11-13 represents a classic example of such a region in humans. These are two distinct neurodevelopmental disorders resulting from abnormalities in at least two genes (or sets of genes) that are imprinted oppositely in this region (Hall 1990; Dittrich et al. 1992; Driscoll et al. 1992; Nicholls 1993). Genes involved in the Prader-Willi syndrome (PWS) are normally expressed exclusively from the paternal allele and those associated with the Angelman syndrome (AS) are normally expressed only from the maternal allele (Mutirangura et al. 1993b; Nicholls 1993, 1994). SNRPN, a small nuclear ribonucleoproteinassociated polypeptide $\mathrm{N}$ gene located in the PWS/AS region is a candidate gene for the PWS (Ozcelik et al. 1992). The murine homolog of this gene, snrpn, has been demonstrated to be expressed exclusively from the paternal homolog (Cattanach et al. 1992; Leff et al. 1992; Ferguson-Smith et al. 1993). The human SNRPN gene is also expressed exclusively from the paternal allele, attributable to genetic imprinting and prominently in the brain (Schmauss et al. 1992; Glenn et al. 1993; Nakao et al. 1994; Reed and Leff 1994; Sutcliffe et al. 1994). Therefore, this system offers the unique opportunity to assess the relationship between replication timing and gene transcription at the chromosomal (allele-specific) and cellular (tissue-specific) levels.

Fluorescence in situ hybridization (FISH) analysis of interphase nuclei has been demonstrated to be efficient and effective for determining the replication timing of chromosomal regions (Selig et al. 1992). A number of genomic regions known to replicate early in S-phase, such as the human c-myc, murine $A d a$, murine $D H F R$ genes (Goldman et al. 1984; Holmquist 1987), and human PYGM gene (Selig et al. 1992), and late replicating genes, such as human and murine $\beta$-globin, murine $\alpha$-fetoprotein, and murine serum albumin (Epner et al. 1981; Goldman et al. 1984; Holmquist 1987) have now been analyzed by FISH. In each case the replication timing values obtained by FISH correspond very well to the timing assigned to these sequences by conventional methods (Selig et al. 1992; Kitsberg et al. 1993a; P.H. Gunaratne, K. Bilyeu, L.G. Shaffer, and A.C. Chinault, in prep.). The ability to compare the replication timing of chromosomal homologs in the same nucleus by taking advantage of their spatial separation in interphase nuclei is especially valuable for studying the replication timing topography of imprinted regions, which show differences in the transcription patterns of homologous alleles.

In an effort to elucidate the complex interplay between replication timing and differential gene transcription we have carried out a systematic analysis of the replication timing properties of a 750-kb region, including the human SNRPN gene. Asynchronous replication was observed throughout, in agreement with previous results (Kitsberg et al. 1993a; Knoll et al. 1994). However, a PWS replication timing domain, encompassing a 500- to 650$\mathrm{kb}$ region, has been identified where the first allele replicates relatively late in lymphocytes, but predominantly early in neuroblasts. This domain appears to be coincident with a transcription domain containing a cluster of transcripts that are expressed prominently in the brain and exclusively from the paternal allele. Analysis of replication timing patterns in a PWS family containing a microdeletion at the $5^{\prime}$ end of the SNRPN gene has also revealed a putative replication timing control region that appears to regulate the time of replication of the paternal copy of the PWS domain in a transcription-independent manner.

\section{Results}

The PWS replication timing domain colocalizes with an imprinted transcription domain

The transition of a given region from the nonreplicated state to the replicated state that occurs during the S-phase of the cell cycle can be monitored by fluorescence microscopy of interphase nuclei after hybridization with specific probes in situ. The unreplicated state is represented by two single hybridization dots (singlets) and the replicated state is represented by two double hybridization dots (doublets). Probes that yield a high percentage of doublet-containing nuclei in a random asynchronous population identify regions that replicate early in S-phase, whereas probes yielding a low percentage of doublet-containing nuclei identify regions replicating late in S-phase.

We have used interphase dual color FISH to examine systematically the replication timing topography of the PWS region on human chromosome 15q11-13. Figure 1 shows representative results obtained using a SNRPN probe (cosmid c93) and cosmid c4-3 (a probe located $\sim 800 \mathrm{~kb}$ more centromeric in the $4-3 \mathrm{R}$ region of the PWS/AS region) for simultaneous in situ hybridization to normal diploid human lymphocytes. Figure 1A shows a metaphase spread, and Figure 1, B-K displays the different replication states of $S N R P N$ and c4-3 encountered in interphase nuclei during this analysis. By examining the fluorescence patterns in 100 nuclei, it was found that cosmid c93 gave a hybridization pattern consistent with late replication in normal lymphocytes $[20 \%$ singlet/ doublet (SD), 4\% doublet/doublet (DD)]. To characterize further the PWS domain containing the SNRPN gene and to delineate the proximal and distal replication timing boundaries separating it from the two early domains flanking it, cosmid clones from a contig developed from the chromosomal region covered by yeast artificial chromosoms (YACs) 457B4 and 132D4 (Nakao et al. 1994; Sutcliffe et al. 1994) were used to carry out replication timing analyses centromeric and telomeric to cosmid c93. The resultant replication timing profile of the PWS 

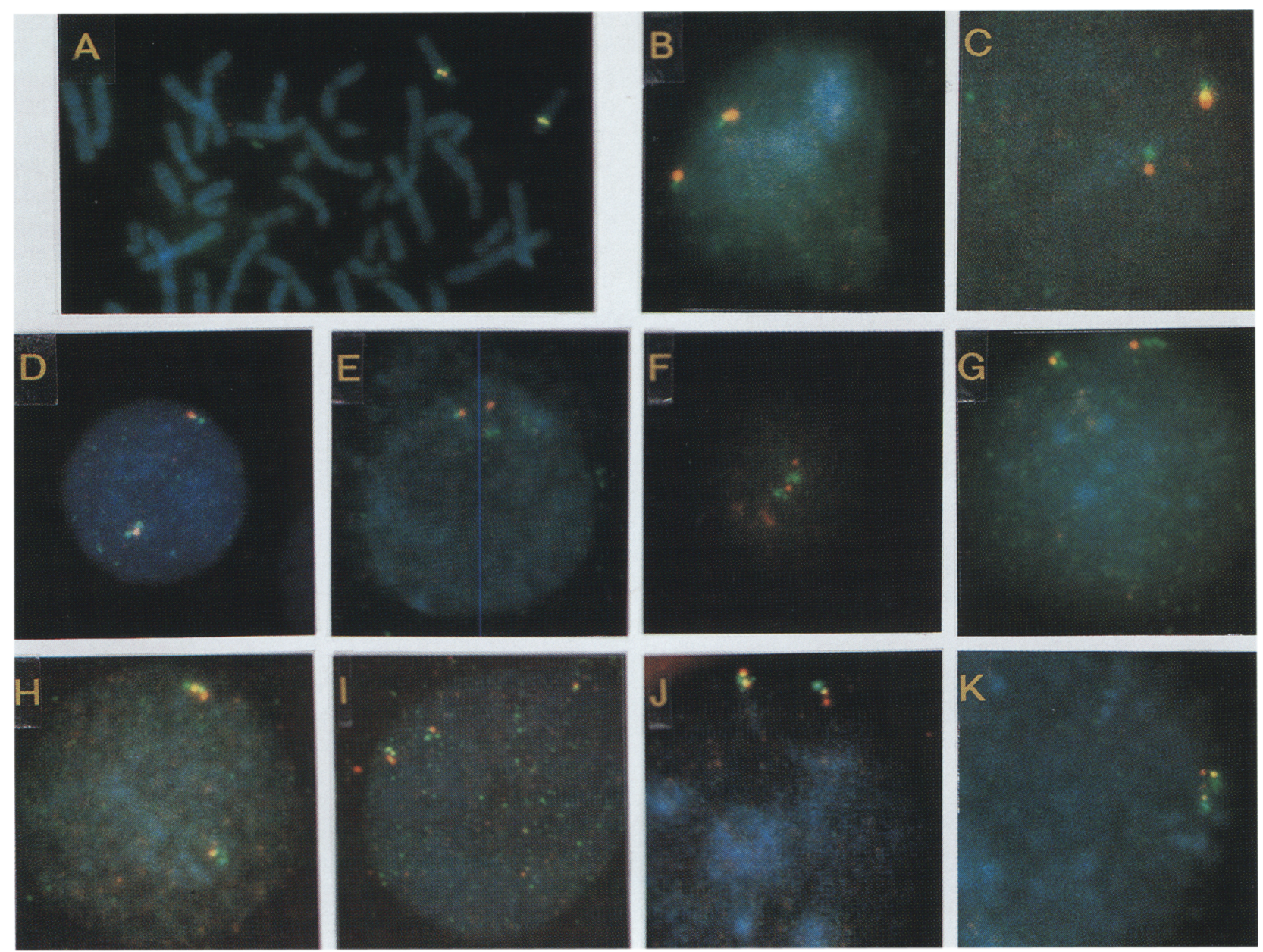

Figure 1. Dual color FISH of cosmids c 93 and c4-3 to normal human lymphocyte nuclei. Cosmid c93 spans the $S N R P N$ region and the c4-3 cosmid contains early-replicating sequences from the $4-3 \mathrm{R}$ region located $\sim 800 \mathrm{~kb}$ more centromeric. Cosmid DNA was labeled with digoxigenin or biotin, hybridized to nuclear spreads, and detected by red or green fluorescence, respectively, as described in Materials and methods. (A) A partial metaphase chromosome spread showing two sets of signals in the two homologous 15 q11-13 regions. $(B-K)$ The major interphase scenarios encountered in this study (patterns that accounted for $<5 \%$ of the total are not shown). $(B, C)$ Interphase nuclei in which neither the c4-3 region nor the c93 region has replicated, giving two sets of single hybridization dots. $(D, E)$ Nuclei in which the c93 region has not yet replicated (visualized as two red singlets), but one copy of the c4-3 region has replicated asynchronously (visualized as one green singlet and one green doublet). $(F, G)$ Nuclei in which the c93 region is unreplicated (red singlets) and both copies of the c4-3 region have apparently replicated (green doublets), although the hybridization signal corresponding to one of the alleles of c4-3 in $G$ appears as three dots, which could result from hybridization of the c4-3 cosmid to a related sequence in the region (Dittrich et al. 1993). (H,I) Nuclei in which the c93 region has replicated only one copy (visualized as one red singlet and one red doublet), whereas both copies of $\mathrm{c} 4-3$ have replicated (two green doublets). (J,K) Nuclei in which both the $\mathrm{c} 93$ and c4-3 regions have completed replication (visible as combinations of red, green, and yellow signals, with the latter resulting from superimposition of red and green signals).

domain is shown in Figure 2. The range of values obtained with cosmid c4-3, which was hybridized simultaneously in each case, is also indicated. This probe was used as a hybridization control because it gave good signals under a variety of conditions and appeared to be the earliest replicating sequence in this region that could be resolved from the other signals. However, the range of timing values found for $\mathrm{c} 4-3$ was greater than the typical $5 \%-10 \%$ level observed with many other probes (Kitsberg et al. 1993a; P.H. Gunaratne, unpubl.); this may be attributable to the presence of related sequences in this region (Dittrich et al. 1993), which could give redundant signals in the absence of replication under certain conditions. For this reason, primary data for each test cosmid are given without normalization to values obtained from this probe. Approximately $500 \mathrm{~kb}$ of DNA in the region spanned by cosmids c106 to $\mathrm{c} 17$ exhibited late replication similar to $S N R P N$. A switch to early replication was observed at cosmid c119 on the centromeric side and at cosmid c39 on the telomeric side. Cosmid c119 (covering $\sim 40 \mathrm{~kb}$ ) on the centromeric side and cosmids c39 and c36 hybridized together and spanning 


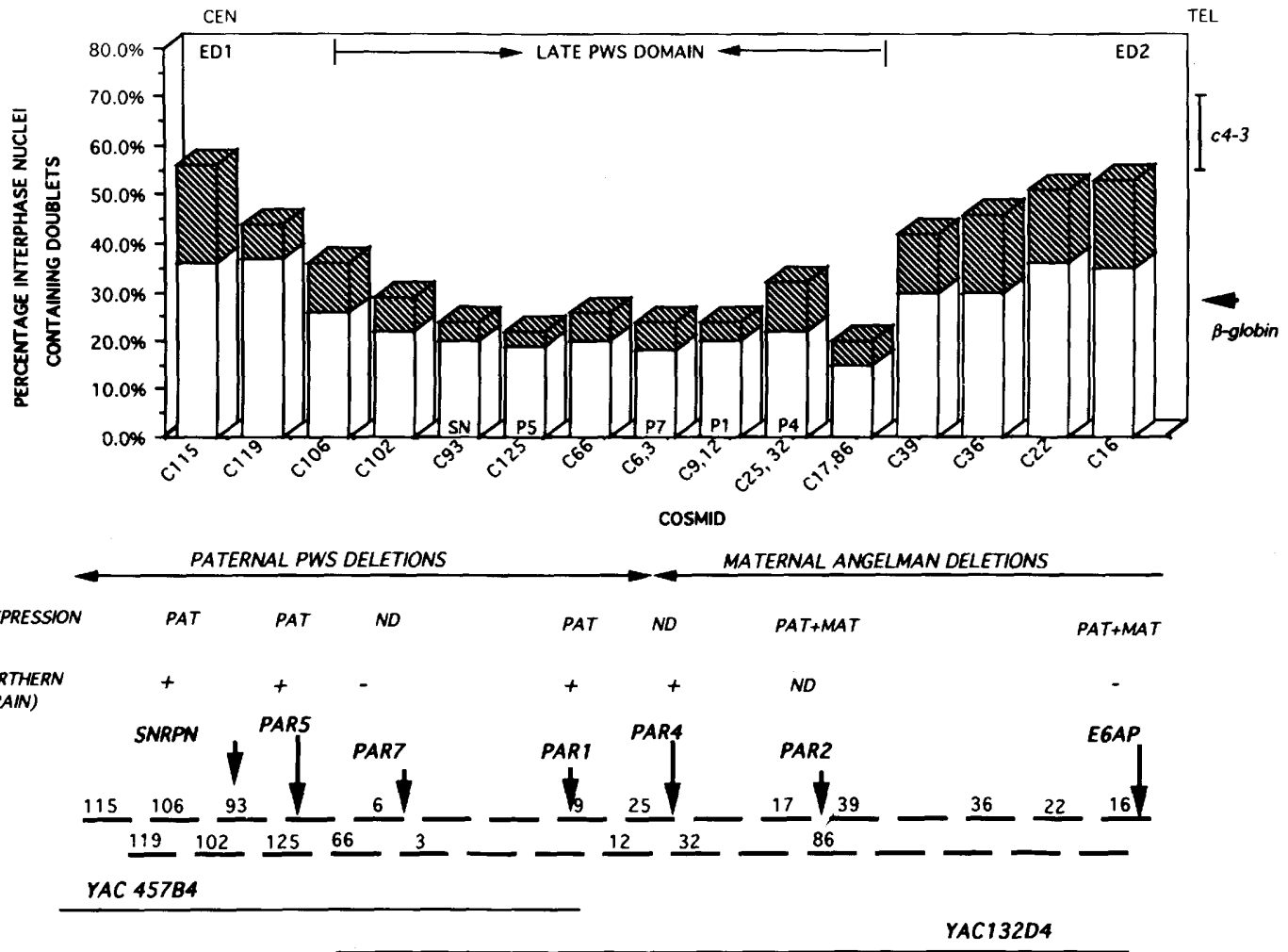

Figure 2. Delineation of the PWS replication timing domain in human lymphocytes. The percentage of interphase nuclei showing doublets in FISH analyses with cosmid clones spanning SNRPN and flanking regions are displayed. The replication timing of regions homologous to each cosmid has been ascertained simultaneously with that of a hybridization control probe homologous to an early-replicating region (c4-3) in dual color FISH experiments. A schematic of the cosmid contig spanning the region analyzed is shown (bottom). The percentage of nuclei containing one homolog in the replicated state and the other in the unreplicated state (\% SD) in each case is represented by the open bars and the percentage of nuclei showing both homologs in the replicated state (\%DD) is represented by the hatched bars. The range of values obtained for the control cosmid c4-3, as well as the value for $\beta$-globin, are shown on the right. The region extending from $\mathrm{c} 106$ to $\mathrm{c} 86$ exhibits a late replication timing profile; ED1 and ED2 represent two flanking early replicating domains. The approximate map positions of five transcripts expressed from the PWS domain (SNRPN, PAR-5, PAR-7, PAR-1, PAR-4) and their expression patterns are shown above the cosmid contig, and the corresponding cosmids are indicated.

$\sim 80 \mathrm{~kb}$ on the telomeric side gave intermediate times of replication. Therefore, the size of the PWS replication domain is estimated to be $500-650 \mathrm{~kb}$.

Nakao et al. (1994) have isolated and mapped seven cDNA clones (SNRPN, PAR-5, PAR-7, PAR-1, PAR-4, PAR-2, and E6-AP| to this region. The SNRPN transcript and four distal transcripts (PAR-5, PAR-7, PAR-1, and PAR-4) localize within the late replicating PWS domain. Two transcripts (PAR-2 and E6-AP) map in the distal early replicating domain. A reverse transcriptase-polymerase chain reaction (RT-PCR)-based imprinting assay (Nakao et al. 1994; Sutcliffe et al. 1994) indicates that the two transcripts localizing in the early replicating domain telomeric to the PWS domain are expressed from both the maternal and paternal homologs, and therefore are not imprinted. In contrast, three of the five transcripts localizing in the PWS domain, SNRPN, PAR-5, and PAR-1, are expressed exclusively from the paternal homolog. The other two transcripts in this domain (PAR-7 and PAR-4) have not been tested for imprinting because of low expression of these transcripts in fibroblasts and lymphoblasts, and a lack of suitable restric- tion site polymorphisms in the mature mRNA for allelespecific expression analysis. Furthermore, the expression of SNRPN, PAR-5, and PAR-1 transcripts appears to be tightly linked under the control of a paternal imprinting control element and SNRPN, PAR-5, PAR-1, and PAR-4 transcripts are all expressed prominently in the brain (Nakao et al. 1994, Sutcliffe et al. 1994). Thus, the late replicating PWS domain mapped in this study is coincident with a transcriptional domain expressing at least five transcripts, of which four are expressed at high levels in the brain and at least three are expressed exclusively from the paternal allele under the control of a common putative imprinting control element.

\section{DNA in the PWS domain exhibits replication timing asynchrony}

The degree of replication timing asynchrony between chromosomal homologs is determined by the fraction of nuclei containing one single hybridization dot (unreplicated) and one double hybridization dot (replicated) for a given probe as shown in Figure 1, $\mathrm{H}$ and I. The open bars 
in the graph shown in Figure 2 represent the percentage of $\mathrm{SD}$, and the hatched bars, the percentage of $\mathrm{DD}$ (where both copies have replicated). In contrast to most autosomal sequences, all of the cosmids tested in the PWS domain detected a high level of asynchrony with $20 \%-30 \%$ of the cells in the population showing SD patterns. The background level of nuclei showing one single hybridization dot and one double hybridization dot per probe attributable to suboptimal hybridization has been estimated to be $<10 \%$ (Selig et al. 1992; Kitsberg et al. 1993a; P.H. Gunaratne, unpubl.).

The PWS domain DNA switches from a late replicating region in lymphocytes to an early replicating region in neuroblasts

Figure 3 summarizes the replication timing results with cosmid c93 (containing the SNRPN gene) relative to other sequences in the critical PWS region and to an unlinked gene region in both lymphocytes and neuroblasts. The replication timing of the first allele of a specific locus to undergo replication is represented by the percentage of singlet/singlet (SS) and the replication timing of the later replicating allele is represented by (percent SS + percent SD). From data presented in Figure 3 it is apparent that the first $S N R P N$ allele to replicate switches from a late replicating region in lymphocytes (75\% singlets) to an early replicating region in neuroblasts (45\% singlets). In contrast, the later replicating allele of $S N R P N$, as well as both alleles of c19 (mapping close to the LS6-1 marker located $\sim 1 \mathrm{Mb}$ telomeric to $S N R P N)$, and the $\beta$-globin control show no significant differences in replication timing between the two tissue types. Although it was not possible in this case to determine unequivocally the parent of origin of each allele, these results would be most consistent with the prediction that the expressed paternal allele, which should be transcribed at higher levels in neuroblasts, also becomes earlier replicating in this tissue, whereas the late replicating, imprinted maternal allele is unchanged.

To determine the extent of the chromosomal region exhibiting this switch from late replication in lymphocytes to earlier replication in neuroblasts, the replication timing of the entire PWS domain DNA was analyzed in human neuroblasts. Figure 4 shows the comparative replication timing profiles of the PWS region in lymphocytes (A) and neuroblasts (B). With the exception of cosmids $\mathrm{c} 3$ and $\mathrm{c} 6$ (containing the PAR-7 transcript), sequences in the PWS domain were all found to replicate early and asynchronously $(35 \%-40 \% \mathrm{SD}, 10 \% \mathrm{DD})$ in these cells. Interestingly, the PAR-7 region, replicating relatively late in neuroblasts, contains the only transcript that is expressed at low levels in neuroblasts.

A microdeletion in the $5^{\prime}$ region of the SNRPN gene results in the loss-of-replication timing control

of this domain when inherited on the paternal chromosome

The replication timing properties of a subset of cosmid clones spanning the five known transcribed regions in
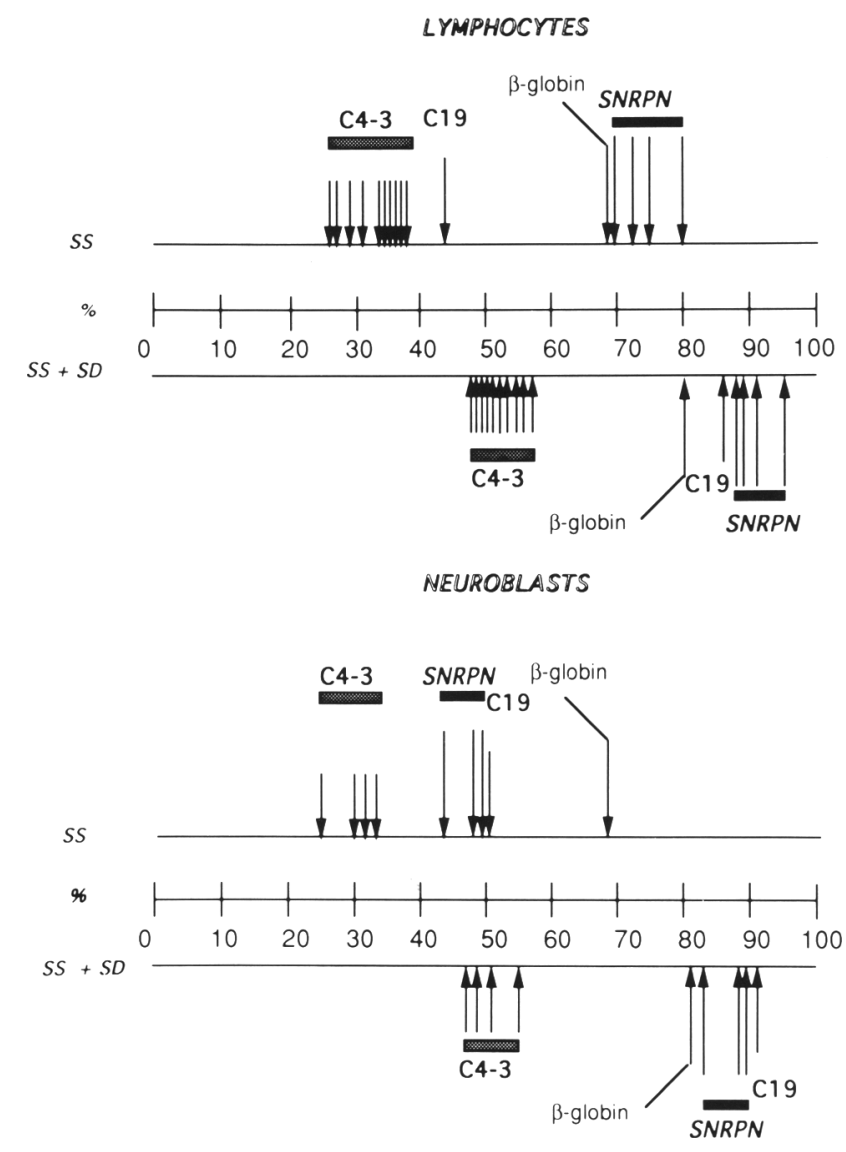

Figure 3. Comparative replication timing of the $S N R P N$ region in lymphocytes and neuroblasts. In each case the timing of $S N$ $R P N$ (cosmid c93) has been assessed in dual color FISH experiments in relation to a probe from a more centromeric domain (c4-3/4-3R) located $\sim 800 \mathrm{~kb}$ away. The replication timing values for a probe from a more telomeric domain, c19, which is located just distal to LS6-1 ( 1 Mb from the SNRPN gene), as well as for an unlinked control probe from the human $\beta$-globin gene region, were also ascertained in both tissues. (Top) Results from lymphocytes are represented; (bottom) results from neuroblasts (neuroblastoma line NBL-S). Each arrow represents a single experiment. The labeled bars represent the distribution of replication timing values specific to $S N R P N$ and $\mathrm{c} 4-3$, respectively. Arrows above the replication timing axis show the percentage of nuclei containing singlet/singlet signals (\%SS) for each probe and represent the replication timing value of the allele undergoing replication first. Arrows below the replication timing axis shows the percentage of nuclei containing singlet/ singlet and singlet/doublet signals $(\% \mathrm{SS}+\% \mathrm{SD})$ collectively and represent the later replicating allele in the same nucleus.

the PWS domain were also analyzed in lymphoblasts of a PWS patient O (Orstavik 1992) carrying a deletion on the paternal chromosome and of the unaffected father $\mathrm{O}$ carrying this deletion on the maternal chromosome (Fig. 5). This patient has been shown to carry a 5- to $30-\mathrm{kb}$ deletion that extends from the $5^{\prime}$ region of $S N R P N$ into the first exon (Sutcliffe et al. 1994). This deletion has been shown to result in the loss of transcription of SNRPN and two downstream imprinted genes (PAR-5 and PAR1), although the deletion does not include the DNA en- 

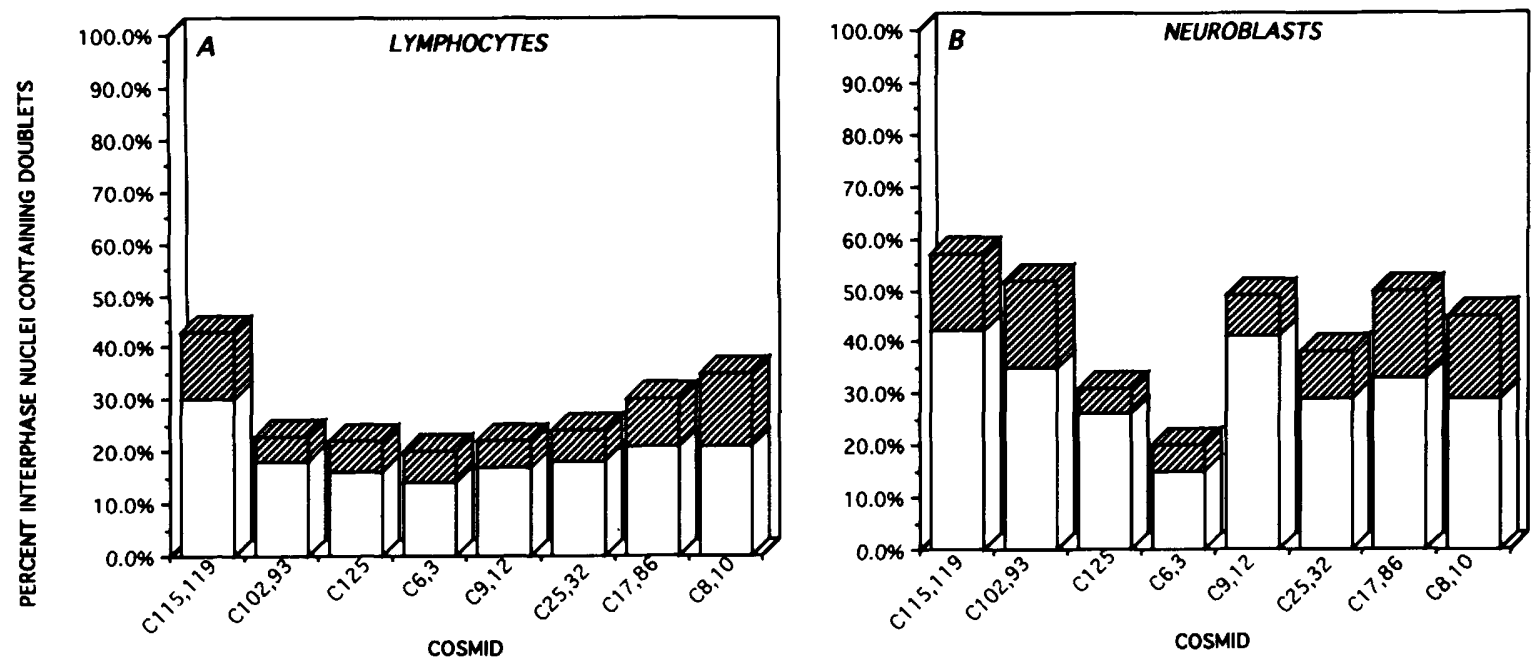

Figure 4. Comparative replication timing properties of the PWS domain in normal human lymphocytes $(A)$ and a human neuroblastoma line NBL-S $(B)$. Timing values were determined with a subset of the cosmids used for analysis of this region in Fig. 2 , plus cosmids c8 and c10 from a region just proximal to LS6-1, located $\sim 1 \mathrm{Mb}$ telomeric. Replication timing obtained with each cosmid is denoted as a percentage of interphase nuclei containing doublets. The open bars represent the percentage of nuclei containing one homolog in the unreplicated state and the other in the replicated state $(\% \mathrm{SD})$. The hatched bars represents the percentage of interphase nuclei in which both homologs had completed replication (\%DD). Cosmid $\mathrm{c} 4-3$ gave average values of $25 \% \mathrm{SD}, 32 \%$ DD for lymphocytes and $14 \%$ SD, $27 \%$ DD for neuroblasts. A $\beta$-globin control gave $12 \%$ SD, $19 \%$ DD for lymphocytes and $13 \%$ SD, $18 \%$ DD for neuroblasts.

coding these transcripts (Sutcliffe et al. 1994). Figure 5 shows the replication timing profiles of PWS domain sequences in the SNRPN, PAR-5, PAR-7, PAR-1, and PAR-4 regions in lymphoblasts of patient $\mathrm{O}$ (Fig. 5A) and the father (Fig. 5B). The replication timing of a $\beta$-globin control was not significantly different in the lymphoblasts of patient $\mathrm{O}$ or the father as compared with normal individuals. In contrast, the PWS domain region in patient $\mathrm{O}$ (Fig. 5A) gave replication timing values more similar to the two early replicating flanking domains described previously in normal cells (see Fig. 2). Surprisingly, the replication timing profile of the PWS domain in the father $\mathrm{O}$ (Fig. $5 \mathrm{~B}$ ) was found to be similar to that seen in normal lymphocytes (see Fig. 4A). In both cases, asynchronous replication of the two alleles was still observed. These results suggested an allele-specific effect of the microdeletion on the replication timing of the PWS domain. However, from these experiments it was not possible to determine the parental origin of the affected allele. Therefore, two strategies were used to determine whether the allele that underwent a change in replication timing in patient $\mathrm{O}$ was of maternal or paternal origin.

The first approach was to use dual color FISH with cosmid c102, labeled with digoxigenin and the classic satellite probe for centromere 15 labeled with biotin on cells from patient $\mathrm{O}$, an affected sibling $\mathrm{A}$ and the father O. Cosmid c102 contains sequences from the region of the deletion, and also appears to have undergone a further internal deletion because of its instability during propagation in Escherichia coli, as it contains only a 30$\mathrm{kb}$ insert. Consequently, under stringent washing conditions this cosmid failed to hybridize to chromosomes carrying the 15q deletion, yielding a single signal colocalizing with the 15 centromere on metaphase spreads and interphase nuclei (Fig. 6). Thus, the replication timing value obtained for the visible signal in each case would represent timing of the SNRPN region on the nondeleted chromosome. As shown in Table 1, patient $\mathrm{O}$ $(9 \%$ and $8 \%$ doublets) and patient $\mathrm{A}(8 \%$ and $7 \%$ doublets) yielded very low values of replicated doublets, indicating that the chromosome carrying the nondeleted allele is late replicating. The father $\mathrm{O}$ yielded higher replication timing values (17-25\% doublets), indicating that the nondeleted allele in this case is earlier replicating. These data are consistent with the conclusion that the early replicating allele of SNRPN in the patients is associated with the paternal chromosome and the late replicating allele with the maternal chromosome.

The second approach used to determine whether the chromosome showing altered replication properties in patients $\mathrm{O}$ and $\mathrm{A}$ was maternal or paternal involved dual color FISH experiments with cosmid $\mathrm{cl02}$ labeled with biotin and cosmids $\mathrm{c} 9 / \mathrm{c} 12$ labeled with digoxigenin. Cosmid 102 (green, G) hybridizes to the normal chromosome, but fails to hybridize to the deleted chromosome and, therefore, allows one to distinguish the $\mathrm{c} 9 / \mathrm{c} 12$ (red, R) signals on the normal or deleted chromosomes by linkage or nonlinkage to $\mathrm{c} 102$. As shown in Figure 7, the red signal (c9/c12) linked to the green signal (c102) identifies the maternal $\mathrm{cl} 02$ and $\mathrm{c} 9 / \mathrm{c} 12$ regions in patients $\mathrm{O}$ and $\mathrm{A}$ and the paternal $\mathrm{cl} 22$ and $\mathrm{c} 9 / \mathrm{cl} 2$ regions in the father. Conversely, the unlinked red signal identifies the paternal $\mathrm{c} 9 / \mathrm{cl} 2$ region in patients $\mathrm{O}$ and $\mathrm{A}$ and the maternal $\mathrm{c} 9 / \mathrm{c} 12$ region in the father $\mathrm{O}$. Results given in Table 2 indicate that the first $\mathrm{c} 9 / \mathrm{c} 12$ allele to replicate in 

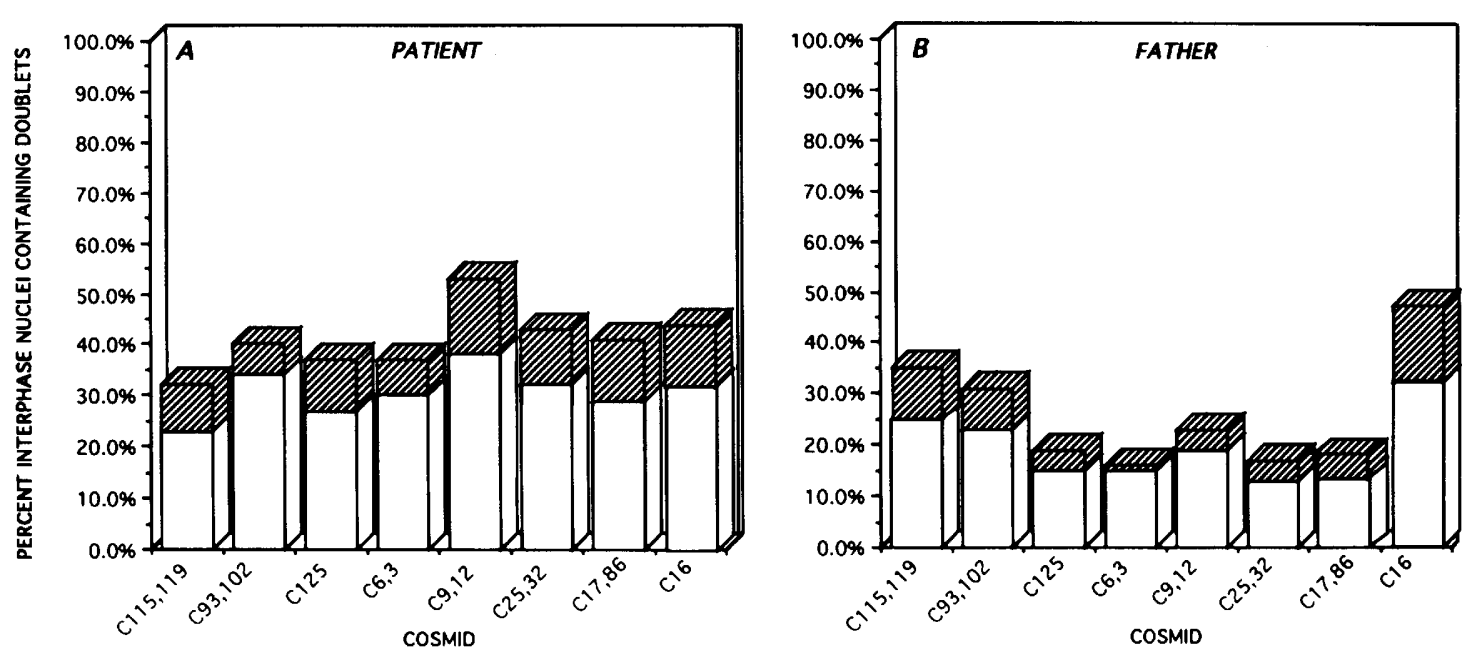

Figure 5. The comparative replication timing properties of the PWS domain sequences in PWS patient $\mathrm{O}$ and the father $\mathrm{O}$. Replication timing values are represented as a percentage of nuclei containing doublets. The open bars represent the percentage of SD; the hatched bars, the percentage of DD. Cosmids containing sequences homologous to the five PWD transcripts, SNRPN, PAR-5, PAR-7, PAR-1, PAR-4, as well as a cosmid containing PAR2 and cosmids cl15/c119 and c16 from flanking centromeric and telomeric domains, respectively, were analyzed with respect to their replication timing in lymphoblasts. $(A)$ Results from patient $\mathrm{O}$ who inherited the deletion paternally and was diagnosed with the PWS. $(B)$ Results from the father of patient $O$ who inherited the deletion maternally and, therefore, was unaffected by the syndrome. The average of values obtained with $\mathrm{c} 4-3$ and $\beta$-globin controls for patient $\mathrm{O}$ were $18 \%$ $\mathrm{SD}, 55 \% \mathrm{DD}$ and $13 \% \mathrm{SD}, 15 \% \mathrm{DD}$, respectively. The average values obtained with $\mathrm{c} 4-3$ and the $\beta$-globin controls for the father $\mathrm{O}$ were $25 \% \mathrm{SD}, 39 \% \mathrm{DD}$ and $11 \% \mathrm{SD}, 17 \% \mathrm{DD}$, respectively.

the father is the allele linked to c102 [8\% (RRG,R -$)+$ $12 \%$ (RRGG, $R-$ ) in experiment 1 and $4 \%(R R G, R-)+$ $17 \%$ (RRGG, R- ) in experiment 2] and, therefore, is the paternal allele on the normal chromosome. Only a small minority of cells showed the unlinked $\mathrm{c} 9 / \mathrm{c} 12$ allele on the deleted chromosome replicating before the linked c9/c12 allele on the nondeleted chromosome in father $\mathrm{O}$ [ $\%$ ( $R G, R R-1]$ in both experiments. In contrast, the most prominent group of cells having undergone replication in patients $\mathrm{O}$ and $\mathrm{A}$ belong to the $(\mathrm{RG}, \mathrm{RR}-\mid$ state (33\% and $29 \%$ for patient $\mathrm{O}$ and $34 \%$ and $29 \%$ for patient A), where the unlinked allele on the deleted paternal chromosome has undergone replication before the linked allele on the normal maternal chromosome. As noted before, the replication timing of the paternal allele of $\mathrm{c} 9 / \mathrm{c} 12$ in these patients has changed from the $17-20 \%$ $\mathrm{SD}$ in normal lymphocytes, indicating earlier replication of this allele. One potential explanation for this could be a breakdown of the boundaries of this domain, such that the PWS domain DNA is now replicated under the control of early replicating sequences in the flanking domains. These results confirm that the deletion resulted in a change of replication timing of the chromosome carrying the deletion when inherited paternally, but did not influence the chromosome carrying the deletion when inherited maternally. The influence of the deletion on the replication timing profile of the PWS domain when inherited paternally is limited to the paternal chromosome without affecting the maternal chromosome as replication asynchrony is maintained. From this study we conclude that the 5 - to $30-\mathrm{kb}$ deletion in the $5^{\prime}$ region of $S N R P N$ affects the replication timing of the paternal chromosome only in cis, and fails to affect the replication timing of the maternal chromosome in cis or trans configuration.

\section{Discussion}

The elucidation of mechanisms and factors controlling the establishment of global replication and transcription patterns requires detailed analyses of large chromosomal regions, both in terms of replication timing properties and transcriptional properties of resident genes. Genes that are expressed differentially on the basis of their chromosomal origin and tissue type, such as SNRPN, offer the ideal system to study these issues. Approximately $3-4 \mathrm{Mb}$ of contiguous DNA including the PWS/ AS region located on human chromosome 15q11-13 has been cloned in YACs and $750 \mathrm{~kb}$ of contiguous sequences in the $S N R P N$ region have been cloned subsequently in cosmids (Kuwano et al. 1992; Mutirangura et al. 1993a; Nakao et al. 1994|. Prior studies on replication in the PWS/AS region were directed at assessing the relationship between genetic imprinting and asynchronous allele-specific replication timing by analysis of a total of eight phage or cosmid clones distributed along the 3- to 4-Mb PWS/AS interval (Kitsberg et al. 1993a; Knoll et al. 1994). In contrast, our work focuses on the systematic comparative analysis of the replication timing and transcriptional properties of a contiguous $750-\mathrm{kb}$ region encompassing the SNRPN gene in normal lymphocytes, in which this region has been shown to be imprinted, in neuroblast tissue, in which the majority of transcripts show predominant expression and in a PWS 

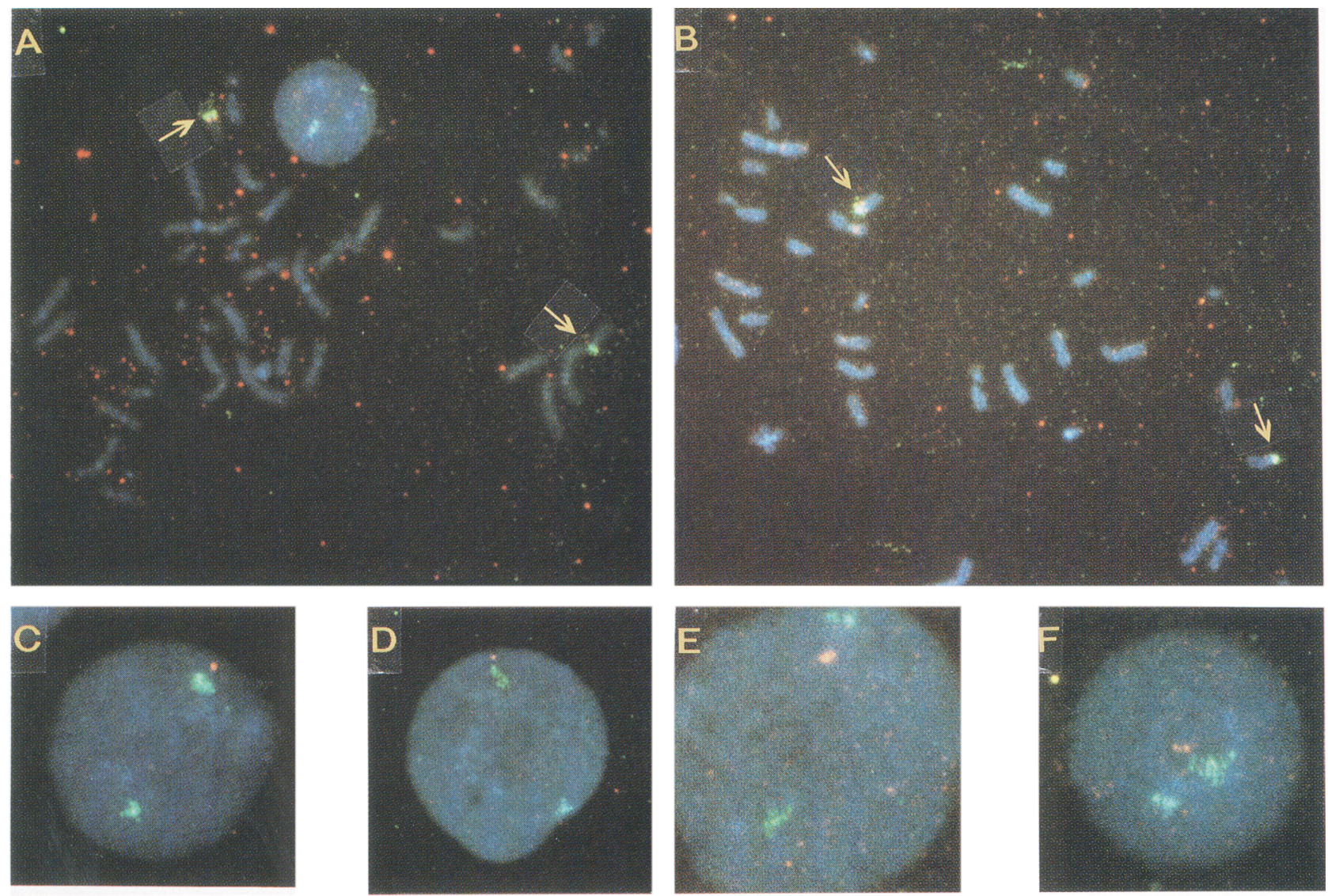

Figure 6. Determination of the replication timing of the unperturbed paternal and maternal alleles of $S N R P N$ in patient $O$ and father. Dual color FISH was performed with c102 labeled with digoxigenin and the classic satellite probe for centromere 15 (D15Z1) labeled with biotin. Cosmid c102 spans the $15 \mathrm{q}$ deletion in this family and under stringent post-hybridization washing conditions hybridizes to the undeleted chromosome but fails to hybridize to the deleted chromosome. (A) A metaphase chromosome spread from the father (O). The digoxigenin signal (c102) is seen colocalizing with the biotin centromere signal on one set of chromosomes and not the other. The chromosome containing the digoxigenin signal should correspond to the paternal chromosome, which is normal, and the chromosome lacking a digoxigenin signal should be the deleted maternal chromosome. $(B)$ A metaphase chromosome spread from patient $\mathrm{O}$. The chromosome containing the digoxigenin signal in this case should correspond to the undeleted chromosome that is maternally inherited and the chromosome lacking the signal should be the paternally inherited chromosome carrying the deletion. $(C, D)$ The $S N R P N$ locus (probe c102) occurring in the unreplicated singlet state on the chromosome that does not carry the deletion (paternal in the father and maternal in patient O). $(E, F)$ The SNRPN locus (probe c102) associated with the nondeleted chromosome occurring in the replicated doublet state. A summary of results from this experiment is given in Table 1.

patient lymphoblastoid line, in which this region has undergone loss of imprinting control.

Replication timing of sequences in the PWS domain was measured by analyzing 100 interphase nuclei subjected to fluorescence in situ hybridization with cosmid probes from the region. On the basis of fluorescent activated cell sorting (FACS) analysis, $\sim 50-60 \%$ of these were in S-phase. Three independent experiments of total sample size 100 each with the SNRPN probe in lymphocytes indicated that there was no significant difference between the percent $S S, S D$, and DD values from experiment to experiment. This was also found to be the case with three independent experiments with this probe in neuroblasts. In contrast, a $t$-test performed on the pairwise combinations of each of these sets between the two tissue types indicated that there was a significant differ- ence between the replication timing values of the $S N R P N$ region in lymphocytes and neuroblasts $(\mathrm{P}<0.95)$. The values obtained for different replication states were also generally consistent with expectations based on cell cycle analyses by FACS (see Materials and methods). However, it is important to avoid overinterpretation of individual absolute timing values with respect to position in the cell cycle because of both biological and technical limitations that are intrinsic to this method. Therefore, whenever possible we have attempted to present primary data and compare trends or profiles based on multiple probes, rather than on statistical analyses of multiple experiments with single probes. From the lymphocyte study, it appears that there is a PWS domain of $\sim 500-650 \mathrm{~kb}$, which is coordinately replicated later than flanking sequences and appears to cor- 
Table 1. Determination of the replication timing of the normal chromosome in family $O$

\begin{tabular}{lccc}
\hline Cell line & Total & $\begin{array}{c}\text { Unreplicated } \\
(\% \mathrm{~S})\end{array}$ & $\begin{array}{l}\text { Replicated } \\
(\% \mathrm{D})\end{array}$ \\
\hline Patient O & 100 & 91 & 9 \\
(normal chromosome $=$ maternal) & 100 & 92 & 8 \\
Patient A & 100 & 92 & 8 \\
(normal chromosome $=$ maternal) & 100 & 93 & 7 \\
Father O & 100 & 78 & 22 \\
(normal chromosome $=$ paternal) & 100 & 75 & 25 \\
& 100 & 83 & 17 \\
& 100 & 78 & 22 \\
\hline
\end{tabular}

(\%S and \%D) The percentage of nuclei with the undeleted copy of the c102 region in the unreplicated and replicated states, respectively, in family $O$. In the case of patients $O$ and $A$ this refers to the maternally inherited chromosome, and in the case of father $O$ this refers to the paternally inherited chromosome. Fig. 6 shows representative nuclei with the c102 region on the normal (undeleted) chromosome in the unreplicated and replicated states.

respond to a coregulated transcriptional domain. If there is an obligatory relationship between replication and transcription, this region would be predicted to replicate asynchronously with the maternal and paternal copies replicating at different times in S-phase according to their respective transcription patterns. Such asynchronous replication within the PWS/AS region has been observed previously by retrospective metaphase analysis (Izumikawa et al. 1991) and interphase FISH analysis (Kitsberg et al. 1993a; Knoll et al. 1994). The 25\%-40\% level of asynchrony reported in the latter two studies is consistent with the $20 \%-30 \%$ level of asynchrony we have observed in the SNRPN region. From the high expression of $S N R P N$ and other nearby genes in the brain one might predict that this domain would be replicated earlier in neuroblasts, which was found to be the case.

A microdeletion of 5-30 kb involving the $5^{\prime}$ end and first exon of $S N R P N$, but not extending into the telomeric transcripts, has been shown to result in the loss of expression of the three imprinted transcripts in the domain, indicating that they are under common transcriptional control although the DNA encoding them extends $>200 \mathrm{~kb}$. These observations are particularly interesting because this small deletion also resulted in the loss of replication timing control of this domain in lymphoblasts. A similar correlation was reported by Forrester et al. (1990) who showed a coordinate loss of gene expression and replication timing control in the human $\beta$-globin gene region. Normal erythroid cells containing a functional locus-activating region (LAR) exhibit expression of $\beta$-globin, DNase I hypersensitivity, and early replication of the same region. A $25-\mathrm{kb}$ deletion removing the LAR of the $\beta$-globin gene cluster resulted in the loss of expression of $\beta$-globin, resistance of the region to DNase I, and late replication in erythroid cells of a thalassemia patient. From such data, one may speculate that elements involved in the global control of gene expression, such as the $\beta$-globin LAR or locus control region (LCR) and the PWS imprinting control region (ICR), may colocalize with elements controlling replication timing.

Although the small deletion in patient $O$ resulted in gene inactivation and methylation of a normally hypom- ethylated paternal NotI site, the replication timing of the resident DNA switched from late to early, which is not consistent with predictions based on other transcription patterns. A possible explanation for this is that loss of the PWS domain late replication control elements may have prompted early replication control elements located in the flanking regions to take over the replication of this domain. In agreement with that is the observation that the replication timing of DNA in the PWS domain in the lymphoblasts of the deletion patient strongly resembles that of sequences from flanking DNA. Evidence was presented by Kitsberg et al. (1993b) to establish that a deletion patient lacking the origin used to replicate the $\beta$-globin gene resulted in the replication of this region in the opposite direction under the control of another nearby origin. An alternative explanation is based on a suggestion made by Yoshida et al. (1993) that late replication is maintained actively by specific trans-acting factors and early replication is a constitutive state. The loss of late replication control elements then would be expected to release this domain from the regulated state replicating late in S-phase to the constitutive state replicating early.

The replication timing control region identified in this study appears to control the replication of the paternal copy of the PWS domain in cis and has no effect on the replication of the paternal copy in trans or the replication of the maternal copy in cis or trans. Therefore, this region must contain allele-specific replication timing control elements responsible for replicating the paternal copy of the PWS domain before initiating the replication of the maternal copy. If the early replicating property of the paternal copy is controlled actively by this region and the maternal copy is late replicating by default because of lack of control, a deletion on the paternal chromosome would result in late replication of the paternal copy giving a synchronous late/late pattern. If the early replicating property of the paternal copy and the late replicating property of the maternal copy are both maintained actively by this same element a deletion on the maternal chromosome would be expected to change the timing on the maternal chromosome in the father $\mathrm{O}$. 

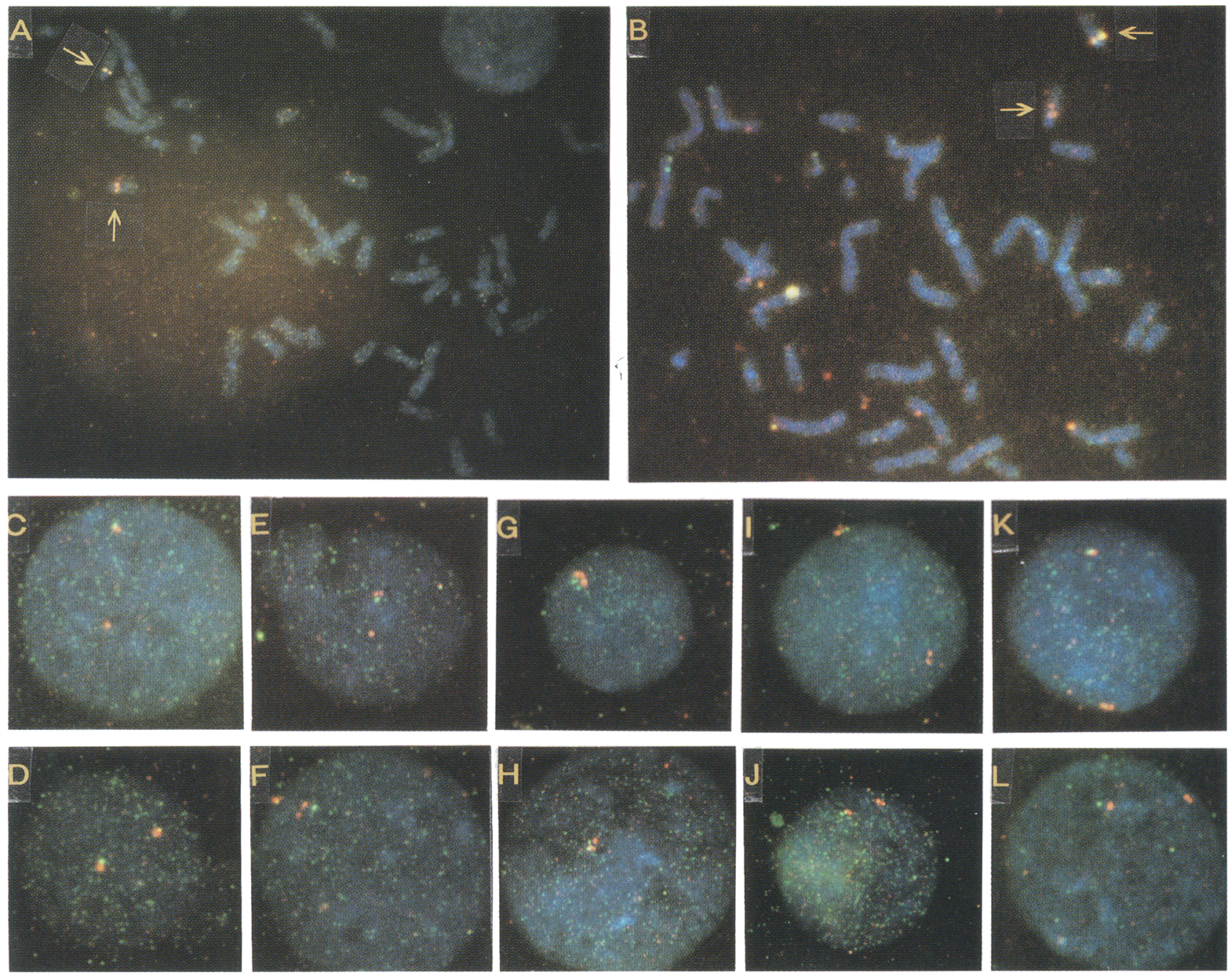

Figure 7. Determination of the parent of origin of the affected chromosome. Dual color FISH was performed with cosmids $\mathrm{c} 9$ and $\mathrm{c} 12$ labeled with digoxigenin (red, R) and cosmid c102 labeled with biotin (green, G). Metaphase spreads from the father $(\mathrm{O})$ and patient $(\mathrm{O})$ are shown in $A$ and $B$, respectively. $(C, D)$ Nuclei in which neither of the $\mathrm{c} 102$ alleles nor the $\mathrm{c} 9 / \mathrm{c} 12$ region on the undeleted chromosome has replicated, visualized as all singlets $[R(G), R(-\| . \mid E, F)$ Nuclei in which the $\mathrm{c} 9 / \mathrm{c} 12$ region has undergone asynchronous replication, being replicated (red doublet) only on the undeleted chromosome defined by linkage to the cl02 single green signal; the linked c102 region and the $\mathrm{c} 9 / \mathrm{c} 12$ region on the deleted chromosome have yet to replicate $[\mathrm{RR} / \mathrm{G}), \mathrm{R}(-\|)(G, H) \mathrm{Nuclei}$ in which both the $\mathrm{cl} 102$ and $\mathrm{c} 9 / \mathrm{c} 12$ regions on the undeleted chromosome have replicated (red and green doublets) and the $\mathrm{c} 9 / \mathrm{cl} 2$ region on the deleted chromosome is unreplicated (red singlet unlinked to a green c102 signal) [RR(GG), R(- )]. (I,J) Nuclei in which the linked cl02 and $\mathrm{c} 9 / \mathrm{c} 12$ regions on the undeleted chromosome (occurring as red and green doublets) and the unlinked $\mathrm{c} 9 / \mathrm{c} 12$ region on the deleted chromosome (red doublets) have all completed replication [RR(GG), RR(-\|). $(K, L)$ Nuclei in which the linked c9/c12 (red) and cl02 (green) regions on the undeleted chromosome have not yet replicated occurring as red and green singlets. The red doublets correspond to the $\mathrm{c} 9 / \mathrm{c} 12$ region occurring in the replicated state on the deleted chromosome $[R(G), \mathbf{R R}(-1]$. Results from this study are summarized in Table 2 .

Because neither case was observed it appears that the replication timing of the paternal copy and the maternal copy of the PWS region is controlled by two different regions. The lack of influence of the deletion on its homolog in the trans configuration indicates also that the paternal-specific and maternal-specific replication timing control regions may be independent of each other. In all situations examined, replication asynchrony was retained. Therefore, this property of imprinted regions may be attributable to an entirely different set of "communication" controls affecting more extended regions of homologous chromosomes. This is supported by previous studies of allele-specific replication timing associated with a number of markers in the PWS/AS region (Kitsberg et al. 1993a; Knoll et al. 1994). For example, for probes mapping near the markers DN34, 4-3R, 189-1, PW71, TD3-21, and GABRB3 the paternal alleles were shown to replicate early, whereas the maternal alleles 
Table 2. Replication timing of the paternal and maternal copies of the SNRPN and c9/12 regions in family $O$

\begin{tabular}{|c|c|c|c|c|c|c|}
\hline \multirow{2}{*}{$\begin{array}{l}\text { Chromosome } \\
\text { deletion } \\
\text { normal }\end{array}$} & \multicolumn{2}{|c|}{$\begin{array}{l}\text { Patient O } \\
\text { (paternal } \\
\text { deletion) }\end{array}$} & \multicolumn{2}{|c|}{$\begin{array}{l}\text { Patient A } \\
\text { (paternal } \\
\text { deletion) }\end{array}$} & \multicolumn{2}{|c|}{$\begin{array}{l}\text { Father O } \\
\text { (maternal } \\
\text { deletion) }\end{array}$} \\
\hline & $\mathrm{R}(-)$ & $\mathrm{RR}(-)$ & $\mathbf{R}(-)$ & $\mathrm{RR}(-)$ & $\mathbf{R}(-)$ & $\mathbf{R R}(-)$ \\
\hline & \multicolumn{6}{|c|}{ Experiment 1} \\
\hline $\mathrm{RG}$ & 52 & 33 & 49 & 34 & 69 & 2 \\
\hline RRG & 1 & 4 & 2 & 3 & 8 & 2 \\
\hline RGG & 1 & 一 & - & 1 & - & - \\
\hline \multirow[t]{2}{*}{ RRGG } & - & 8 & - & 11 & 12 & 7 \\
\hline & \multicolumn{6}{|c|}{ Experiment 2} \\
\hline RG & 57 & 29 & 60 & 29 & 70 & 2 \\
\hline RRG & 1 & 4 & 1 & 5 & 4 & 2 \\
\hline RGG & - & 1 & - & - & 1 & - \\
\hline RRGG & - & 8 & - & 5 & 17 & 4 \\
\hline
\end{tabular}

$\mathrm{R}$ and $\mathrm{RR}$ correspond to $\mathrm{c} 9 / 12$ labeled with digoxigenin (red $=$ $R$ ) in the unreplicated and replicated states, respectively. G and GG correspond to c102 labeled with biotin (green $=\mathrm{G}$ ) in the unreplicated and replicated states, respectively. The chromosome carrying the deletion of the $\mathrm{cl} 02$ region is denoted, and the associated $\mathrm{R}$ or $\mathrm{RR}$ signal corresponds to the $\mathrm{c} 9 / 12$ region on the deleted chromosome (paternal in patients $\mathrm{O}$ and $\mathrm{A}$ and maternal in father $\mathrm{O}$. One hundred nuclei were analyzed for each experiment. Situations where the $\mathrm{c} 9 / 12$ region on the chromosome carrying the deletion replicated before the homologous region on the nondeleted chromosome replicated are shown in bold.

replicated late. In contrast, at the GABRA5 locus it was observed that the maternal allele replicated early and the paternal allele replicated late. The replication timing of the most telomeric probe examined, which overlaps with the marker IR10, has been reported by Knoll et al. (1994) to exhibit mosaic asynchrony with no allele specificity in timing and by Kitsberg et al. (1993a) to exhibit a paternal-early and maternal-late pattern. Clearly, additional work is needed to understand how replication asynchrony is established and maintained.

The $5^{\prime}$ region of SNRPN appears to contain elements involved in the establishment or maintenance of the allele-specific replication timing and transcription patterns associated with the genetically imprinted PWS region. The replication of the paternal and maternal PWS domain copies appears to be under the control of distinct and independent control regions. Further dissection of sequences in the allele-specific replication timing control region identified in our study may allow us to identify and characterize some of the regulatory elements controlling transcription and replication and understand the basis of the relationship between these important genetic properties and their influence on the phenomenon of genetic imprinting in mammals.

\section{Materials and methods}

\section{Cell cultures}

Normal human lymphocytes, patient lymphoblasts, and the hu- man neuroblastoma line NBL-S (Cohn et al. 1990) were cultured in RPMI supplemented with $10 \%$ FBS. The lymphoblast and neuroblast cultures were grown in RPMI to log phase before use. Normal lymphocytes were prepared by passing $10 \mathrm{ml}$ of peripheral blood through $\mathrm{Na}^{+}$-heparin tubes to prevent coagulation. This sample was transferred into a leucoprep tube and spun at $2500 \mathrm{rpm}$ for $10 \mathrm{~min}$ to separate the lymphocytes from the red blood cells and plasma. The buffy coat containing the lymphocytes $(\sim 1 \mathrm{ml})$ was transferred into a T25 flask with $10 \mathrm{ml}$ RPMI/ $10 \%$ FCS and grown for $72 \mathrm{hr}$ at $37^{\circ} \mathrm{C} / 5 \% \mathrm{CO}_{2}$.

\section{FACS analysis of cell lines used for interphase FISH}

Approximately $2 \times 10^{6}$ cells were spun down and resuspended in $2 \mathrm{ml}$ of $0.9 \% \mathrm{NaCl}$. The cells were fixed by vortexing at low speed and simultaneously adding $5 \mathrm{ml}$ of $95 \%$ ETOH and incubating for $30 \mathrm{~min}$ at room temperature. The samples were spun down and cells resuspended in $1 \mathrm{ml}$ of $50 \mu \mathrm{g} / \mathrm{ml}$ of propidium iodide treated with $20 \mu \mathrm{l}$ of $5 \mathrm{mg} / \mathrm{ml}$ RNase for $20 \mathrm{~min}$ at $37^{\circ} \mathrm{C}$. The samples were then subjected to FACS analysis on an Epics Profile Analyzer (Coulter Corporation) of the Baylor College of Medicine/ Department of Cell Biology. In the cases of the normal lymphocytes and the lymphoblasts of the father O, FACS was also performed on samples prepared by fixation with methanol-glacial acetic acid to see if the fixation protocols used for FISH changed the FACS profile. The results were as follows: Normal lymphocytes (ethanol fixed) $=40 \% \mathrm{G}_{1}, 57 \% \mathrm{~S}, 2 \% \mathrm{G}_{2}$; normal lymphocytes (methanol fixed) $=36 \% \mathrm{G}_{1}, 53 \% \mathrm{~S}, 7 \% \mathrm{G}_{2}$ patient $\mathrm{O}$ (ethanol fixed) $=32 \% \mathrm{G}_{1}, 61 \% \mathrm{~S}, 5 \% \mathrm{G}_{2} ;$ patient $\mathrm{A}$ (ethanol fixed) $=36 \% \mathrm{G}_{1}, 56 \% \mathrm{~S}, 5 \% \mathrm{G}_{2}$; father $\mathrm{O}$ (ethanol fixed) $=32 \% \mathrm{G}_{1}, 64 \% \mathrm{~S}, 2 \% \mathrm{G}_{2}$; father $\mathrm{O}$ (methanol fixed) $=32 \%$ $\mathrm{G}_{1}, 61 \% \mathrm{~S}, 5 \% \mathrm{G}_{2}$; NBL-S (ethanol fixed) $=44 \% \mathrm{G}_{1}, 51 \% \mathrm{~S}, 4 \%$ $\mathrm{G}_{2}$.

\section{FISH}

FISH was performed as described by Lichter et al. $(1990,1991)$. Unsynchronized cell cultures were treated for 45 min with $10 \mu \mathrm{l}$ of a $10-\mu \mathrm{g} / \mathrm{ml}$ solution of colchicine per milliliter of medium. Cells were harvested and treated with hypotonic $\mathrm{KCl}$ solution $(0.075 \mathrm{M})$ for $20 \mathrm{~min}$ at room temperature and fixed with methanol-glacial acetic acid $(3: 1)$ for $15 \mathrm{~min}$ at room temperature. The cell pellet was washed three times in fixative and dropped on cold wet slides and air dried. The slides were treated with RNase ( $6 \mu \mathrm{g} / \mathrm{slide})$ in $2 \times \mathrm{SSC}$ for $30 \mathrm{~min}$ at $42^{\circ} \mathrm{C}$ and dehydrated in $70 \%, 90 \%$, and $100 \%$ ethanol, followed by air drying. Denaturation was carried out for $2 \mathrm{~min}$ at $70^{\circ} \mathrm{C}$ in $70 \%$ formamide/ $2 \times$ SSC followed by dehydration in ice cold $70 \%, 90 \%$, and $100 \%$ ethanol.

Cosmid DNA was labeled by substituting dTTP with biotin11-dUTP or digoxigenin-11-dUTP at a ratio of 2:1. Standard nick translation reactions using Oncor nonisotopic labeling kit (biotin) or the Boehringer Mannheim nick translation kit (digoxigenin) protocols were carried out at $16^{\circ} \mathrm{C}$ for $90 \mathrm{~min}$. The reaction mixes were inactivated by incubation at $65^{\circ} \mathrm{C}$ for $10 \mathrm{~min}$, followed by ethanol precipitation with $50 \mu \mathrm{g}$ of sonicated single-stranded herring sperm DNA.

Probe DNA (100 ng) was mixed with 1-5 $\mu$ g of human Cot-1 DNA (GIBCO-BRL) and reprecipitated. The DNA mix was resuspended completely in the hybridization solution $160 \%$ formamide $/ 2 \times \mathrm{SSC} / 10 \%$ dextran sulfate). The probe was denatured for $10 \mathrm{~min}$ at $75^{\circ} \mathrm{C}$ and repetitive sequences preassociated for 15 min at $37^{\circ} \mathrm{C}$ before application to the denatured slides. Hybridization was carried out in a moist chamber at $37^{\circ} \mathrm{C}$ overnight.

Posthybridization washes were carried out by incubating the slides in $50 \%-60 \%$ formamide $/ 2 \times \mathrm{SSC}$ at $42^{\circ} \mathrm{C}$ for $20 \mathrm{~min}$, 
followed by two 5 -min washes in $2 \times \mathrm{SSC}$ at $42^{\circ} \mathrm{C}$. A high stringency wash was performed in $0.1 \times \mathrm{SSC}$ at $60^{\circ} \mathrm{C}$ for $10 \mathrm{~min}$. The slides were rinsed in $1 \times$ PBD buffer (Oncor) before the detection steps. Biotin-labeled probes were detected with FITC-avidin (Oncor) for $30 \mathrm{~min}$ at $42^{\circ} \mathrm{C}$. Digoxigenin-labeled probes were detected with anti-digoxigenin antibody conjugated to rhodamine (diluted 1:100) (Boehringer Mannheim) for $30 \mathrm{~min}$ at $42^{\circ} \mathrm{C}$. After three rinses in $1 \times \mathrm{PBD}$ the slides were counterstained with diamidinophenylidole (DAPI) diluted in antifade at a concentration of $100 \mathrm{ng} / \mathrm{ml}$. The slides were visualized by fluorescence microscopy using a Zeiss axiophot microscope equipped with a triple-band pass filter.

\section{Acknowledgments}

We thank Dr. Lisa G. Shaffer for her help in providing human lymphocytes from the Kleberg Cytogenetic Laboratory, Baylor College of Medicine for this study and Kellie Lugenbeel is acknowledged for her help in the interphase FISH analysis. Wendy D. Schober and Dr. Dorothy Lewis at the Baylor College of Medicine FACS facility are acknowledged for performing FACS analysis on all of the cell lines used in this study. We are especially grateful to Dr. Karen H. Orstavik for providing the lymphoblast line from patient $O$. We thank Dr. Bernard Forget of Yale University for providing us with a cosmid clone FC-12 containing the human $\beta$-globin gene region. Helen Salwen and Dr. Susan Cohn are acknowledged for the NBL-S line. P.H.G. and A.C.C. were supported in part by American Cancer Society grant CB-68A. M.N. and J.S.S. are postdoctoral fellows in the laboratory of Dr. Arthur L. Beaudet in the Howard Hughes Medical Institute. This work was supported by NIH grant 8D20619 and a Beneficia Foundation grant to D.H.L.

The publication costs of this article were defrayed in part by payment of page charges. This article must therefore be hereby marked "advertisement" in accordance with 18 USC section 1734 solely to indicate this fact.

\section{References}

Boggs, B.A. and A.C. Chinault. 1994. Analysis of replication timing properties of human X-chromosomal loci by fluorescence in situ hybridization. Proc. Natl. Acad. Sci. 91: 60836087.

Brown, S.W. 1966. Heterochromatin. Science 151: 417-425.

Cattanach, B.M., J.A. Barr, E.P. Evans, M. Burtenshaw, C.V. Beechey, S.E. Leff, C.I. Brannan, N.G. Copeland, N.A. Jenkins, and J. Jones. 1992. A candidate mouse model for PraderWilli syndrome which shows an absence of Snrpn expression. Nature Genet. 2: 270-274.

Cohn, S.L., H. Salwen, M.W. Quasney, I. Naohiko, J.M. Cowan, C.V. Herst, R.H. Kennett, S.T. Rosen, J.A. DiGiuseppe, and G.M. Brodeur. 1990. Prolonged N-myc protein half life in a neuroblastoma cell line lacking $\mathrm{N}-m y c$ amplification. Oncogene 5: 1821-1827.

Dhar, V., A.I. Skoultchi, and C.L. Schildkraut. 1989. Activation and repression of a $\beta$-globin gene in cell hybrids is accompanied by a shift in its temporal replication. Mol. Cell. Biol. 9: 3524-3532.

Dittrich, B., W.P. Robinson, H. Knoblauch, K. Butting, K. Schmidt, G. Gillessen-Kaesbach, and B. Horsthemke. 1992. Molecular diagnosis of the Prader-Willi and Angelman syndromes by detection of parent-of-origin specific DNA methylation in 15q11-13. Hum. Genet. 90: 313-315.

Dittrich, B., H. Knoblauch, K. Buiting, and B. Horsthemke. 1993. Characterization of a DNA sequence family in the
Prader-Willi/Angelman syndrome chromosome region in 15q11-q13. Genomics 16: 269-271.

Driscoll, D.J., M.F. Waters, C.A. Williams, R.T. Zori, C.C. Glenn, K.M. Avidano, and R.D. Nicholls. 1992. A DNA methylation imprint determined by the sex of the parent distinguishes the Prader-Willi and Angelman syndromes. Genomics 13: 917-924.

Edenberg, H.J. and J.A. Huberman. 1975. Eucaryotic chromosome replication. Annu. Rev. Genet. 9: 245-284.

Epner, E., R.A. Rifkind, and P.A. Marks. 1981. Replication of $\alpha$ and $\beta$ globin DNA sequences occurs during early S-phase in murine erythroleukemia cells. Proc. Natl. Acad. Sci. 78: 3058-3062.

Ferguson-Smith, A.C., B.M. Cattanach, S.C. Barton, C.V. Beechey, and M.A. Surani. 1993. Embryological and molecular investigation of parental imprinting on mouse chromosome 7. Nature 351: 667-670.

Forrester, W.C., E. Epner, C.M. Driscoll, T. Enver, M. Brice, T. Papannopoulou, and M. Groudine. 1990. A deletion of the human $\beta$-globin locus activation region causes a major alteration in chromatin structure and replication across the entire $\beta$-globin locus. Genes \& Dev. 4: 1637-1649.

Glenn, C.C., K.A. Porter, M.T.C. Jong, R.D. Nicholls, and D.J. Driscoll. 1993. Functional imprinting and epigenetic modification of the human SNRPN gene. Hum. Mol. Genet. 2: 2001-2005.

Goldman, M.A., G.P. Holmquist, M.C. Gray, L.A. Caston, and A. Nag. 1984. Replication timing of mammalian genes and middle repetitive sequences. Science 224: 686-692.

Hand, R. 1978. Eucaryotic DNA: Organization of the genome for replication. Cell 15: 317-325.

Hall, J.G. 1990. Genomic imprinting: Review and relevance to human disease. Am. J. Hum. Genet. 46: 857-873.

Holmquist, G.P. 1987. Role of replication time in the control of tissue-specific gene expression. Am. J. Hum. Genet. 40: 151173.

Holmquist, G.P., M. Gray, T. Porter, and J. Jordan. 1982. Characterization of Giemsa dark- and light-band DNA. Cell 31: 121-129.

Izumikawa, Y., K. Naritomi, and K. Hirayama. 1991. Replication asynchrony between homologs 15q11.2: Cytogenetic evidence for genomic imprinting. Hum. Genet. 87: 1-5.

Kitsberg, D., S. Selig, M. Brandeis, I. Simon, D.J. Driscoll, R.D. Nicholls, and H. Cedar. 1993a. Allele specific replication timing of imprinted gene regions. Nature 364: 459-463.

Kitsberg, D., S. Selig, I. Keshet, and H. Cedar. 1993b. Replication structure of the human $\beta$-globin gene domain. Nature 366: 588-590.

Knoll, J.H.M., S-D. Cheng, and M. Lalande. 1994. Allele specificity of DNA replication timing in the Angelman/PraderWilli syndrome imprinted chromosomal region. Nature Genet. 6: 41-46.

Kuwano, A., A. Mutirangura, B. Dittrich, K. Butting, B. Horsthemke, S. Saitoh, N. Nikawa, S.A. Ledbetter, A.C. Chinault, and D.H. Ledbetter. 1992. Molecular dissection of the Prader-Willi/Angelman Syndrome region (15q11-13) by YAC cloning and FISH analysis. Hum. Mol. Genet. 1: 417-425.

Latt, S.A. 1973. Microfluorometric detection of deoxyribonucleic acid replication in human metaphase chromosomes. Proc. Natl. Acad. Sci. 70: 3395-3399.

Leff, S.E., C.I. Brannan, M.I. Reed, T. Ozcelik, U. Francke, N.G. Copeland, and N.A. Jenkins. 1992. Maternal imprinting of the mouse Snrpn gene and conserved linkage homology with the Prader-Willi syndrome region. Nature Genet. 2: 259264.

Lichter, P., C.C. Tang, K. Call, G. Hermanson, G.A. Evans, D. 


\section{Gunaratne et al.}

Housman, and D.C. Ward. 1990. High resolution mapping of human chromosome 11 by in situ hybridization with cosmid clones. Science 247: 64-69.

Lichter, P., A.L. Boyle, T. Cremer, and D.C. Ward. 1991. Analysis of genes and chromosomes by nonisotopic in situ hybridization. Genet. Anal. Tech. Applic. 8: 24-35.

Morishima, A., M.M. Grumbach, and J.H. Taylor. 1962. Asynchronous duplication of human chromosomes and the origin of sex chromatin. Proc. Natl. Acad. Sci. 48: 756-763.

Mutirangura, A., A. Jayakumar, J.S. Sutcliffe, M. Nakao, M.J. McKinney, K. Buiting, B. Horsthemke, A.L. Beaudet, A.C. Chinault, and D.H. Ledbetter. 1993a. A complete YAC contig of the Prader-Willi/ Angelman chromosome region (15ql1-q13) and refined localisation of the SNRPN gene. Genomics 18: 546-552.

Mutirangura, A., F. Greenberg, M.G. Butler, S. Malcolm, R.D. Nicholls, A. Chakravarti, and D.H. Ledbetter. 1993b. Multiplex PCR of three dinucleotide repeats in the Prader-Willi/ Angelman critical region (15q11-13): Molecular diagnosis and mechanism of uniparental disomy. Hum. Mol. Genet. 2: 143-151.

Nakao, M., J.S. Sutcliffe, B. Durtschi, A. Mutirangura, D.H. Ledbetter, and A.L. Beaudet. 1994. Imprinting analysis of three genes in the Prader-Willi/Angelman region: SNRPN, E6-associated protein and PAR-2 (D15S225E). Hum. Mol. Genet. 3: 309-315.

Nicholls, R.D. 1993. Genomic imprinting and candidate genes in the Prader-Willi /Angelman syndromes. Curr. Opin. Genet. 3: 445-456.

- 1994. New insights reveal complex mechanisms involved in genomic imprinting. Am. J. Hum. Genet. 54: 733740 .

Orstavik, K.H. 1992. Prader-Willi syndrome in a brother and sister without cytogenetic or detectable molecular genetic abnormality at chromosome 15q11-q13. Am. J. Med. Genet. 44: 534-538.

Ozcelik, T., S. Leff, W.P. Robinson, T. Donlon, M. Lalande, E. Sanjines, A. Schinzel, and U. Francke. 1992. Small nuclear ribonucleoprotein polypepetide $\mathrm{N}$ (SNRPN), an expressed gene in the Prader-Willi syndrome critical region. Nature Genet. 2: 265-269.

Reed, M.L. and S.E. Leff. 1994. Maternal imprinting of human SNRPN, a gene deleted in the Prader-Willi syndrome. $\mathrm{Na}$ ture Genet. 6: 163-167.

Schmauss, C., M.L. Brines, and M.R. Lerner. 1992. The gene encoding the small nuclear ribonucleoprotein-associated polypeptide $\mathrm{N}$ is expressed at high levels in neurons. J. Biol. Chem. 267: 8521-8529.

Schmidt, M. and B.R. Migeon. 1990. Asynchronous replication of homologous loci on human active and inactive X-chromosomes. Proc. Natl. Acad. Sci. 87: 3685-3689.

Selig, S., K. Okumura, D.C. Ward, and H. Cedar. 1992. Delineation of DNA replication time zones by fluorescence in situ hybridization. $E M B O /$. 11: 1217-1225.

Sutcliffe, J.S., M. Nakao, S.L. Christian, K.H. Orstavik, N. Tommerup, D.H. Ledbetter, and A.L. Beaudet. 1994. Deletions of a differentially methylated $\mathrm{C}_{\mathrm{p}} \mathrm{G}$ island at the $S N R P N$ gene define a putative imprinting control region. Nature Genet. 8: $52-58$.

Taylor, J.H. 1960. Asynchronous duplication of chromosomes in cultured cells of Chinese hamster. I. Biophys. Biochem. Cytol. 7: 455-464.

Torchia, B.S., L.M. Call, and B.R. Migeon. 1994. DNA replication analysis of FMR-1, XIST and Factor $8 \mathrm{C}$ by FISH shows nontranscribed X-linked genes replicate late. Am. I. Hum. Genet. 55: 96-104.
Yoshida, I., N. Kashio, and N. Takagi. 1993. Cell fusion-induced quick change in replication time of the inactive $\mathrm{X}$ chromosome: An implication for the maintainence mechanism of late replication. $E M B O J$. 12: 4397-4405. 


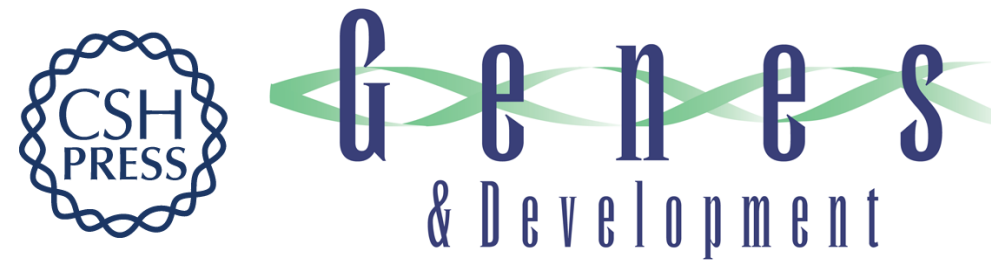

\section{Tissue-specific and allele-specific replication timing control in the imprinted human Prader-Willi syndrome region.}

P H Gunaratne, M Nakao, D H Ledbetter, et al.

Genes Dev. 1995, 9:

Access the most recent version at doi:10.1101/gad.9.7.808

References This article cites 43 articles, 12 of which can be accessed free at:

http://genesdev.cshlp.org/content/9/7/808.full.html\#ref-list-1

License

Email Alerting

Service

Receive free email alerts when new articles cite this article - sign up in the box at the top right corner of the article or click here.

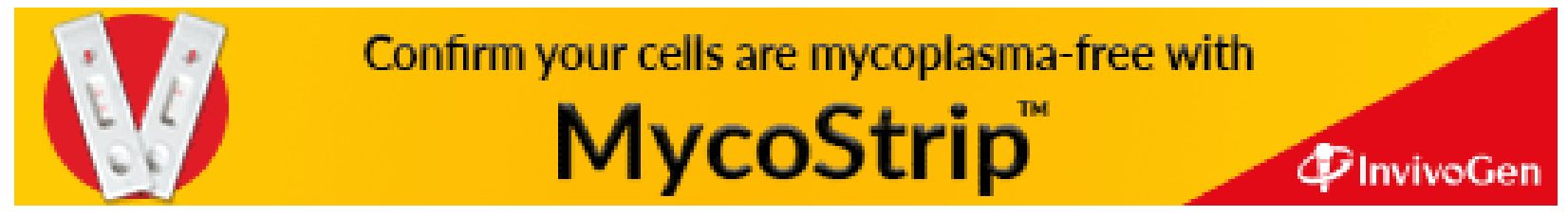

